\title{
Seeking Diversity in the Geosciences When Black Lives Matter
}

Sherilyn Williams-Stroud, Illinois State Geological Survey/University of Illinois Urbana-Champaign, Champaign, Illinois 61820, USA

\section{INTRODUCTION}

The death of George Floyd on 25 May 2020 ignited already high tensions in the U.S. Black community after months of sheltering in place to prevent the spread of COVID-19. Much higher rates of lost lives and jobs occurred in communities of color than in White communities. The confluence of events highlighted systemic inequities for People of Color (POC), making them visible to others. In the mostly peaceful protests that took place all over the world, an interesting and positive observation could be made - there were many White participants, signaling a change in the understanding of the phrase "Black Lives Matter." The wave of protests sparked a wave of a variety of organizations and businesses issuing statements of support. GSA was one of the first organizations to do this, while acknowledging that the geosciences have not done a good job of advancing diversity. The current mindset provides an opportunity for us to interrogate the discipline's failure to achieve equity while it is experiencing a mood of receptive inquiry. This article examines some of the historical data on diversity in the geosciences and cites studies that provide possible reasons why representation has not increased. A recognition of previous and existing programs currently generating more POC geoscientists is key: Building upon them can provide a path to successfully improving diversity in the geoscience community.

\section{NEARLY FOUR DECADES OF DIVERSITY GAINS?}

The concept of "implicit bias" caught fire in recent years as an explanation for how people's choices and expectations impact evaluation, hiring, and promotion decisions. More recently, machine learning applications were expected to eliminate bias because models trained with just data would be free of human bias. One study concluded that judges' bail determinations for the riskiest criminal suspects were incorrect nearly $50 \%$ of the time (Kleinberg et al., 2018). The promise of the machine to eliminate bias was very quickly dampened by the realization of just how difficult it is to keep human biases out of the machine learning process (Zou and Schiebinger, 2018). While we were examining our biases, representation gave way to diversity, thereby softening the focus on parity. The result was that measuring all students and faculty by the same metric prevented the desired increase of those underrepresented in academia (Tapia, 2010).

The numbers of women geoscientists have increased since prior to the start of my professional career at the U.S. Geological Survey in 1988, but I am still usually the only person in my combined category (Black woman geoscientist) in the room. This reality is reflected in the fact that the number of geoscience Ph.D.s awarded to Black and Native American people has remained nearly constant in the 38 years of data shown in Figure 1, obtained from the National Center for Science and Engineering Statistics (NCSES), illustrating where progress has (or has not) been achieved regarding parity of POC in the academy. Parity relative to the U.S. population would mean an earth-science department faculty is $13 \%$ Black, but the portion of Black faculty remains significantly below that, less than $2 \%$. The data analyzed for this article is personally relevant for me; it tracks my involvement in the field starting with my undergraduate study. Since 1980, the proportion of Ph.D.s awarded to Black recipients averaged $2.6 \%$. Martinez-Acosta and Favero (2018) suggested that diversity efforts were unsuccessful because the culture of academia may not truly be inclusive. Organizational culture change resulting from diversity training appears to have been short-lived in most cases, and a study published in the Harvard Business Review found that voluntary diversity programs in the corporate environment are the most effective at achieving equity (Dobbin and Kalev, 2016). These findings are also applicable to academia, consistent with the assertion by Golom (2018) that institutional culture is a significant obstacle to change.

Another possible problem with diversity initiatives is that they are often implemented beneath an umbrella covering all underrepresented groups. The most effective solutions for each group can be different, though overlapping. Conflating diverse groups together may have had a detrimental effect on the success of POC in higher education (Shapiro et al., 2017). In the past few years, the number of white female Ph.D. recipients has reached near parity with White men but Black and other POC still fall significantly short of representation. Issues related to retention, support, advancement, and freedom from sexual harassment have become more important for women than recruitment, as shown in a study done at Columbia University (June, 2018).

\section{DISCUSSION}

Recruiting POC students to earth science is a critical part of the solution. A successful program of recruitment and access that is exposing students to geosciences at the middle to high-school level is the Mathematics, Science, and Engineering Academy (M-SEA) at Fort Valley State University, implemented in 1993 as part of their long standing (ca. 1983) Cooperative Developmental Energy Program (CDEP). A total of 419 STEM graduates have been produced from the programs, 47 of whom received geoscience degrees. An analysis of data on Historically Black Colleges and Universities (HBCUs) from the NCSES shows that more than $30 \%$ of STEM bachelor's degrees awarded to Black 


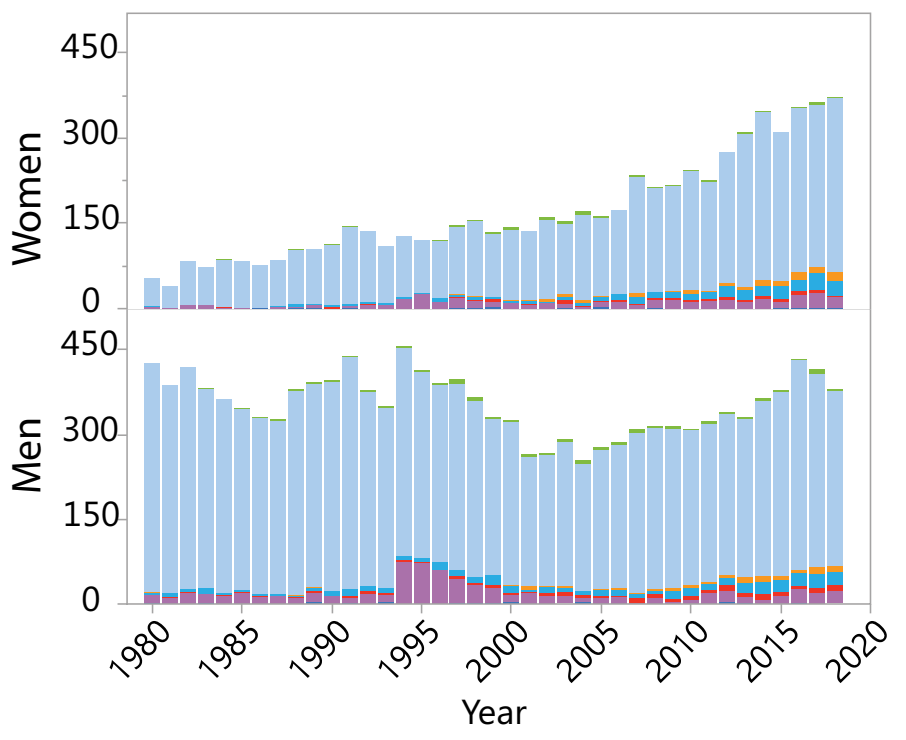

American Indian or Alaska Native, Not Hispanic or Latino

Asian, Not Hispanic or Latino

Black or African American, Not Hispanic or Latino

Hispanic or Latino

More than one race, Not Hispanic or Latino

Other race or race not reported, Not Hispanic or Latino

White, Not Hispanic or Latino

Figure 1. Doctorates awarded in geoscience, atmospheric, and ocean sciences from 1980 to 2018, showing distribution by ethnicity and race. Top histogram shows degrees awarded to women, bottom histogram shows degrees awarded to men. Source: National Center for Science and Engineering Statistics.

Americans were from HBCUs. The relative percentage by field of study varies; HBCUs produce $52 \%$ of Black physicists but only $10 \%$ of Black geoscientists. CDEP has made a very significant contribution to changing these numbers, as this program alone accounts for $\sim 20 \%$ of all geoscience bachelor's degrees from HBCUs. Recognizing this pipeline has important implications because $30 \%$ of Black recipients of a geoscience doctoral degree earned their bachelor's at an HBCU. This kind of relationship is not only true for Black geoscientists, but for POC students in all minority-serving institutions. GeoFORCE at the University of Texas, modeled on the M-SEA program, also encourages students of color to pursue geoscience and is adding POC students to the pipeline.

\section{CONCLUSIONS}

For many years, a commitment to enhance diversity has been expressed by universities and in the private sector, but the numbers indicate a lack of efficacy for those efforts or an inability to turn good intentions into concrete actions. It seems clear that a one-size-fits-all approach to improve diversity does not do so equally across all underrepresented groups. With respect to increasing POC in the geosciences, additional programs modeled after CDEP can fill the pipeline. The biggest challenge for replicating and sustaining these programs is funding, which for CDEP and GeoFORCE comes largely from the private sector because businesses recognized an opportunity to cultivate needed talent. Making geoscience culture more welcoming to POC is only part of the solution, and the critical question is whether the now-enlightened academic geoscience community has the will to adopt and support (financially and otherwise) replications of programs that have proven to increase representation.

\section{REFERENCES CITED}

Dobbin, F., and Kalev, A., 2016, Why diversity programs fail: Harvard Business Review, April, p. 52-60, https://hbr.org/2016/07/why-diversity -programs-fail (accessed June 2020).

Golom, F., 2018, Reframing the dominant diversity discourse: Alternate conversations for creating whole system change: Metropolitan Universities, v. 29 , no. 1, https://doi.org/10.18060/22172.

June, A.W., 2018, What factors hold back the careers of women and faculty of color? Columbia University went looking for answers: The Chronicle of Higher Education, 18 Oct. 2018, https://www .chronicle.com/article/What-Factors-Hold-Back -the/244841 (last accessed 6 Nov. 2020).

Kleinberg, J., Lakkaraju, H., Leskovec, J., Ludwig, J., and Mullainathan, S., 2018, Human decisions and machine predictions: The Quarterly Journal of Economics, v. 133, no. 1, p. 237, https://doi.org/ 10.1093/qje/qjx032.

Martinez-Acosta, V.G., and Favero, C.B., 2018, A discussion of diversity and inclusivity at the institutional level: The need for a strategic plan: Journal of Undergraduate Neuroscience Education (JUNE): A Publication of FUN (Faculty for Undergraduate Neuroscience), v. 16, no. 3, p. A252, http://www.ncbi.nlm.nih.gov/pubmed/30254540 (last accessed 6 Nov. 2020).

Shapiro, D., Dundar, A., Huie, F., Khasiala Wakhungu, P., Yuan, X., Nathan, A., and Hwang, Y., 2017, Signature 12 Supplement: Completing College: A National View of Student Attainment Rates by Race and Ethnicity-Fall 2010 Cohort (Signature Report No. 12b), in National Student Clearinghouse.

Tapia, R.A., 2010, Hiring and developing minority faculty at research universities: Communications of the ACM, v. 53 , no. 3, p. 33, https://doi .org/10.1145/1666420.1666435.

Zou, J., and Schiebinger, L., 2018, AI can be sexist and racist-it's time to make it fair: Nature, v. 559 , no. 7714 , p. 324 , https://doi.org/10.1038/ d41586-018-05707-8.

ManusCript ReCeIVEd 20 July 2020

Revised manuscript Received 24 Sept. 2020

ManUSCRIPT ACCEPTED 22 OCt. 2020 